\title{
Don't defend your values by diluting them : end letters.
}

\author{
Camille Akmut
}

July 22, 2019

\begin{abstract}
A last series of letters that accompanied our research.
\end{abstract}




\section{Half free, half imprisoned. - letter to the FSFE, 22/07}

To : Matthias Kirschner and the rest of the FSFE staff.

In reaction to : 'Public Money Public Code', a petition by the FSFE https://publiccode.eu/

I signed this petition with the following note :

ALL publicly financed software should be Free Software - not just "developed for the public sector". (We don't use words like "open source")

I don't see how it is the FSFE's role to promote 'open source'.

I can perfectly see how it is a "strategic move", and even a "realistic" one... [However :]

The FSFE should set the standards for Free Software in accordance with the FSF and [the] GNU [project] ${ }^{1}$.

We don't defend our values by diluting them.

(unless the FSFE intends to become some sort of center-left [SPD] version of the FSF - figuratively speaking)

\footnotetext{
${ }^{1}$ https://www.gnu.org/philosophy/free-sw.en.html https://www.gnu.org/philosophy/open-source-misses-the-point.html
} 


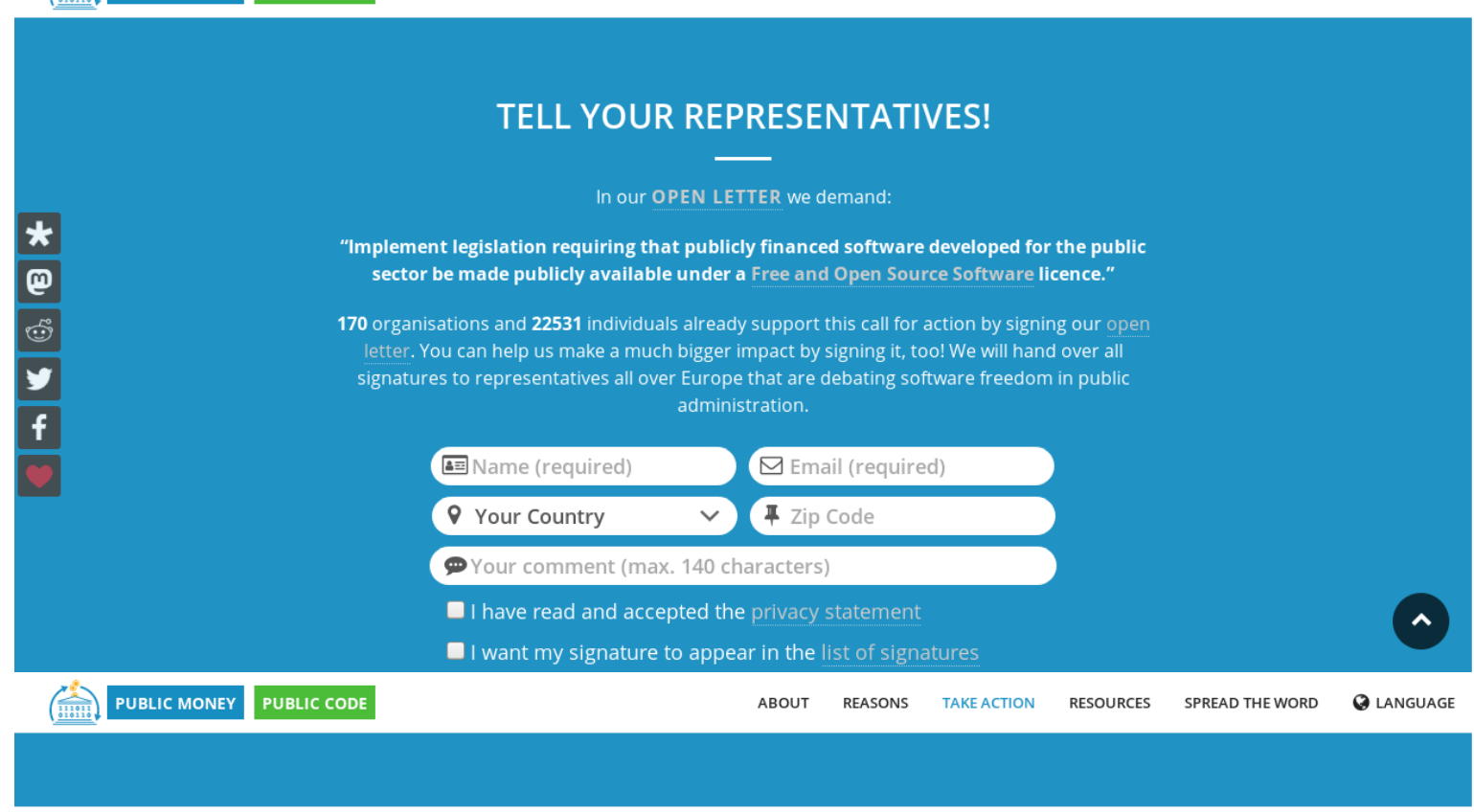

The following organisations support our open letter. If your organisation is also interested in joining the call for Public Code, please contact us.
$\odot$ All
O International NGOS
O Administrations
O National NGOs O Regional NGOs

(14) WORDPRESS FOUNDION

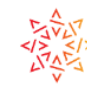<smiles>[CH]1[CH]C=C1</smiles>

4

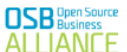

HERME

WIIIMEDIA

$p \equiv p$

debian

Ren opence

๑cceative ดิ<smiles>[10BH]</smiles>

moz:lla
- Edri

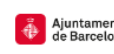

C L Libreoffice

(April)

Tór ifsfe

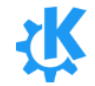

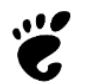




\section{A cyber letter lost - to the $E F F, 22 / 07$}

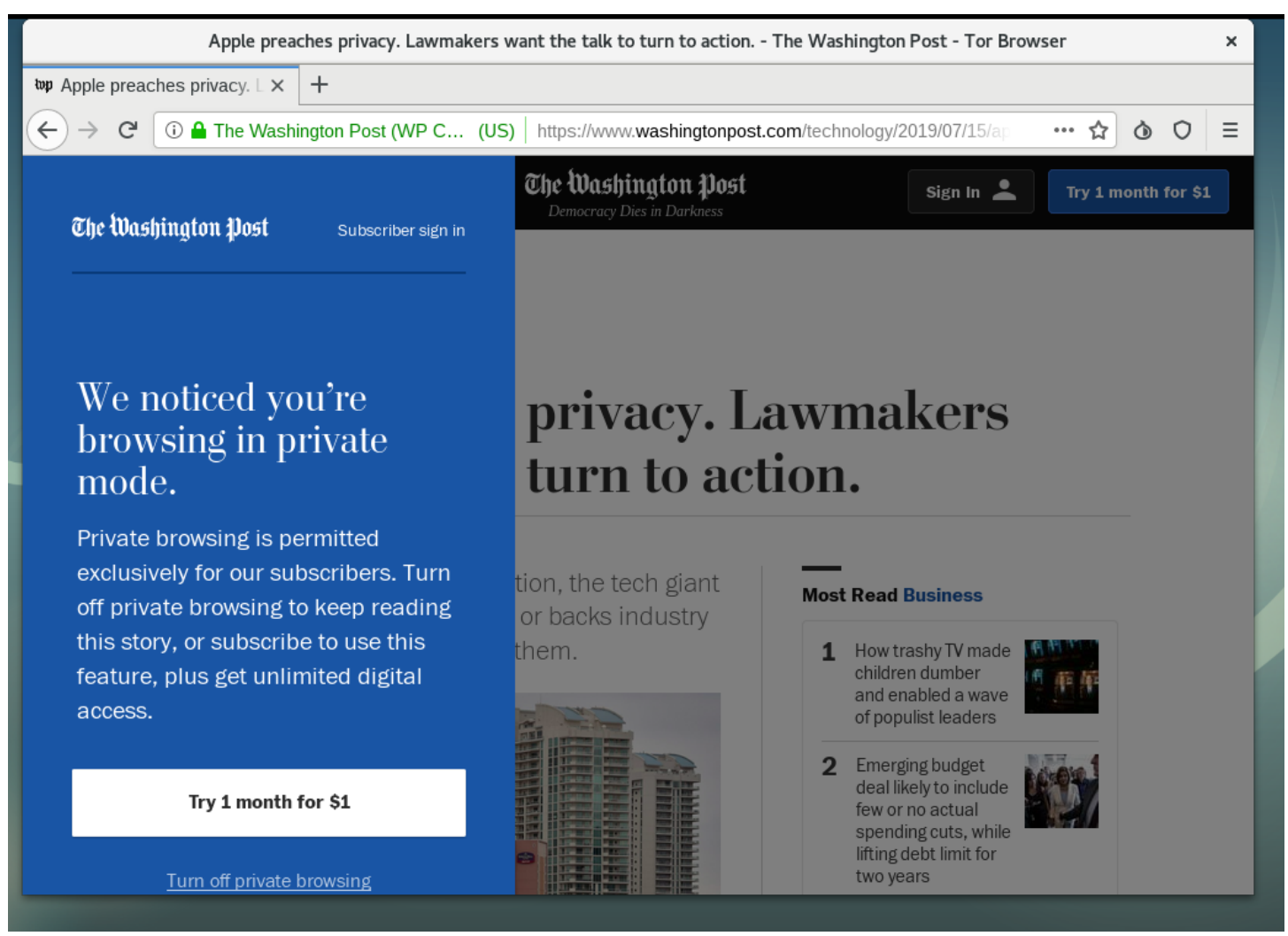

"If you are going to use the value of privacy in your marketing, I think you have an obligation to your consumers to tell us what that means," said India McKinney $(\ldots)^{2}$

This, of course applies, to everyone (EFF included).

As yet another of their staffers publishes in yet another newspaper whose website contradicts their purported values in most obvious ways, we refrained from writing another letter.

Let alone this particular publication being among the properties of one Jeff Bezos (Amazon).

If the Electronic Frontier Foundation weren't so busy fighting "Big gov", it would be what it claims : a defender of privacy against all threats; it is not, and perhaps has never been.

But, like the American Frontier, after which it was most likely named, it has many histories and many delusions...

\footnotetext{
${ }^{2}$ Albergotti and Romm. 2019. "Apple preaches privacy." 15/07, WP.
} 